\title{
Expansion of Application Range of Continuous Welded Rail Integrated with Turnout
}

\author{
Hiroo KATAOKA \\ Senior Researcher,
}

\author{
Hideaki YANAGAWA \\ Senior Researcher, \\ Track Structures \& Components Laboratory, \\ Yuichi IWASA \\ Researcher, \\ Track Technology Division
}

\author{
Yuuki NISHINOMIYA \\ Researcher,
}

\begin{abstract}
We used the finite element method to establish a technique to precisely evaluate the axial force, expansion and contraction of rails in areas with turnouts in succession integrated with a CWR on ballasted track laid on an earth roadbed or on ballastless track of viaduct. We carried out an on-site test in a CWR track section where two turnouts are located in succession integrated with a CWR on a ballasted track, and the test results were compared with the analytical results. We applied this technique to analysis of the rail axial force characteristics of a CWR connected with a turnout directly fastened to viaducts, and clarified the relationship between girder bridge length, girder arrangement and axial force in rails.
\end{abstract}

Keywords: continuous welded rail, turnout, buckling

\section{Introduction}

The effectiveness of a continuous welded rail (CWR) in reducing noise and vibration and improving ride quality has led to an expansion in their scope of application.

In Japan, ballast lateral resistance for meter gauge lines doesn't have so sufficient margin of safety for the track lateral stability needed to prevent track buckling. Accordingly, ballast lateral resistance must be increased in the CWR track integrated with turnout.

In past research, the conditions and methods necessary for installing a turnout integrated with CWR on ballasted track were clarified [1]. However, the conditions for installing multiple turnouts or those for directly fastened track integrated with CWR have not yet been clarified, and an evaluation method taking into consideration combination of multiple turnouts and types of construction such as viaducts has not yet been established. In such cases, expansion joints are currently used at both ends of turnouts.

In this study, an analytical approach using the finite element method was developed to calculate the axial force and longitudinal displacement of rails at turnouts integrated with CWR installed on ballasted track or directly fastened track on viaducts. Field tests on ballasted track equipped with two turnouts integrated with CWR were performed, and the analytical model was verified by comparing the field test results with the analytical model calculation results. We applied this technique to analyzing axial force characteristics of rails at a turnout with ties directly fastened to viaducts integrated with CWR, and clarified the relationship between bridge girder length, girder arrangement and axial force in rails.

\section{FEM approach to analysis of axial force in rails near turnouts integrated with CWR}

Expanding the existing analytical method used for
CWR integrated with a turnout, an analytical approach using the finite element method was developed to calculate the axial force and longitudinal displacement of rails near turnouts integrated with CWR on ballasted track or directly fastened track on viaducts. This analytical method enables calculation them under various track conditions including different turnout types/layouts, rail types and longitudinal/lateral resistance levels. It can be applied to complicated cases with multiple turnouts installed in a railroad depots or rail yards.

In the analytical method, a turnout was modeled as shown in Fig. 2 to represent the actual structure of the turnout shown in Fig. 1. The stock rail and tongue rail of the turnout transmit the longitudinal force mutually through the sleepers near the heel of the point. This force is considered to depend on the rail fastening creep resistance and the elastic deformation of the sleepers and to be proportional to the relative displacement of these two rails, which are considered to be connected to each other with an elastic spring. The spring constant is hereafter referred to as the "restrain spring coefficient", and is decided from experimental results obtained in a heating test on a full-size track with a turnout [2].

The characteristics of this model are as follows:

1) Sleepers are not modeled in the longitudinal direction of the track, and rail nodes are connected to each other with elastic springs. Nodes of rails and girders are connected with non-linear springs representing the longitudinal resistance of sleepers.

In the lateral direction, rail nodes are connected with rigid springs $\left(\mathrm{k}=1.0 \times 10^{8} \mathrm{MN} / \mathrm{m}\right)$ and nodes of rails and girders are connected with non-linear springs representing the lateral resistance of sleepers.

The lateral and longitudinal resistances of sleepers on ballasted track depend on the length of the sleepers in a turnout. The values are estimated using the following empirical formula established for the lateral resistance of sleepers as proposed in Reference [1].

$$
\mathrm{g}_{0}=0.75 \mathrm{~W}+29 \rho \mathrm{Ge}+1.3 \rho \mathrm{Gs}
$$




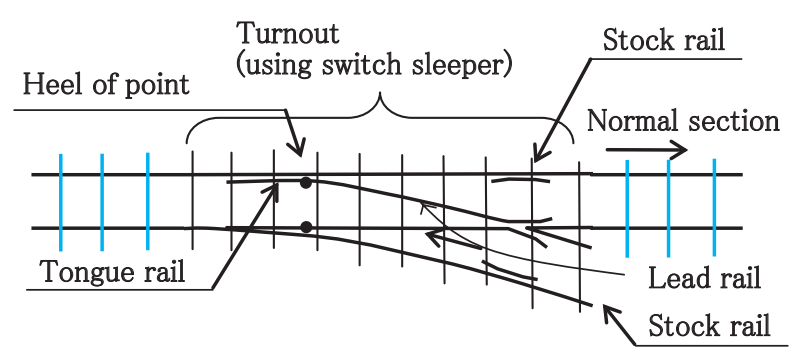

Fig. 1 Turnout

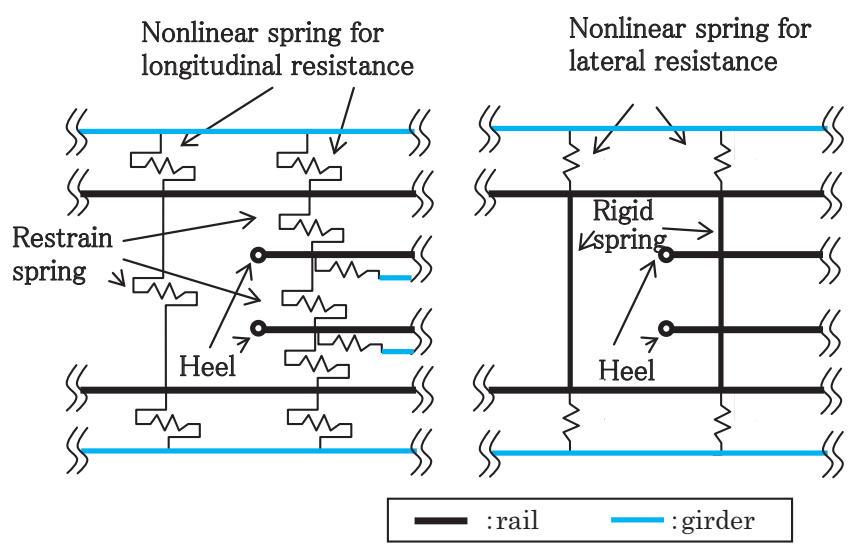

(a) Longitudinal direction

(b) Lateral direction

Fig. 2 Analytical model of turnout (near heel of point)

where

$\mathrm{r}_{0}=0.75 \mathrm{~W}+1.3 \rho \mathrm{Ge}+29 \rho \mathrm{Gs}$

$\mathrm{g}_{0}$ : asymptotic value of lateral resistance of sleeper $(\mathrm{kN})$

$\mathrm{r}_{0}$ : asymptotic value of longitudinal resistance of sleeper $(\mathrm{kN})$

$\mathrm{W}$ : mass of track above sleeper

$\rho$ : mass of ballast per unit volume $\left(\mathrm{kg} / \mathrm{cm}^{3}\right)$

Ge: primary moment of inertia around the upper side of the sleeper's end surface $\left(\mathrm{cm}^{3}\right)$

Gs: primary moment of inertia around the upper side of the sleeper's side surface $\left(\mathrm{cm}^{3}\right)$

The longitudinal resistance of the sleeper is estimated using (2), which is obtained by exchanging Ge and Gs in (1).

The relationship between the longitudinal or lateral resistance and sleeper displacement can be approximately estimated by the following formulas:

$$
\begin{aligned}
& \mathrm{r}=\mathrm{r}_{0} \mathrm{x} /(\mathrm{x}+\mathrm{b}) \\
& \mathrm{g}=\mathrm{g}_{0} \mathrm{y} /(\mathrm{y}+\mathrm{a})
\end{aligned}
$$

where

$\mathrm{r}$ : longitudinal resistance of sleeper $(\mathrm{N} / \mathrm{cm})$

g: lateral resistance of sleeper $(\mathrm{N} / \mathrm{cm})$

$\mathrm{r}_{0}$ : asymptotic value of longitudinal resistance of sleeper $(\mathrm{N} / \mathrm{cm})$

$\mathrm{g}_{0}$ : asymptotic value of lateral resistance of sleeper $(\mathrm{N} / \mathrm{cm})$

$\mathrm{x}$ : longitudinal displacement of sleeper $(\mathrm{cm})$

$\mathrm{y}$ : lateral displacement of sleeper $(\mathrm{cm})$

$\mathrm{b}$ : coefficient showing the characteristics of longitudinal resistance (value of displacement when $r$ reaches half the value of $\left.r_{0}\right)(\mathrm{cm})$

a: coefficient showing the characteristics of lateral resistance (value of displacement when $\mathrm{g}$ reaches half the value of $\left.\mathrm{g}_{0}\right)(\mathrm{cm})$

2) As for the normal track section neighboring the turnouts, the nodes of rails and girders are connected with non-linear springs in the longitudinal and lateral directions. In addition, the nodes of rails and sleepers are connected by rotational resistance springs, and those of rails are connected by rigid springs in the lateral direction of the track.

3) Bridge girders are assumed to expand freely under conditions of temperature change.

4) Rails and girders are modeled using beam elements. As for ballasted track on subgrade, girder elements are not included in the model and rail nodes are connected to fixed nodes by springs representing ballast resistance.

\section{CWR integrated with two turnouts on ballasted track}

\subsection{Field test}

A field test was carried out to verify the analysis method and clarify the characteristics of rail axial force and longitudinal displacements. The test was performed on a CWR section on ballasted track integrated with turnouts of $50 \mathrm{kgN} 8 \#$ and $12 \#$.

The stock rail on the straight line was welded and that on the branch line was not welded behind the turnout. The test site is shown in Fig.3.

Measurement was carried out in summer soon after the welding of the rails, and also in autumn and winter. The axial force in the rails and their temperature were measured continuously using strain gauge over two day period in each of the above seasons. Rail displacement was measured by using a string stretched between alignment markers. The measurement positions are shown in Fig. 4.

Figures 5 and 6 show the measured axial force and the longitudinal displacement of the rails under a temperature change of $26.7^{\circ} \mathrm{C}$. For rail displacement, a plus sign (+) represents displacement to the right in Fig. 4. In the figures, the axial force and the displacement of two rails are shown. The analyzed values in the figure are described in Section 3.2.

The axial force at the heels of points on the rails is between 1.0 and 1.2 times that of the rails in the normal section under the temperature change of $26.7^{\circ} \mathrm{C}$. The displacements of adjacent rails at the heels of points Y11 and Y12 are different.

\subsection{Verification using test results}

The analysis method outlined in Chapter 2 was verified using the field test results described above. The analysis conditions are shown in Table 1 based on those of the field test track. The temperature change was set at $26.7^{\circ} \mathrm{C}$ which is the maximum value for summer. It was assumed that the movable rail end to be taken into account in the calculation was positioned far $(250 \mathrm{~m})$ from the turnout.

The asymptotic value of resistance for sleepers in 


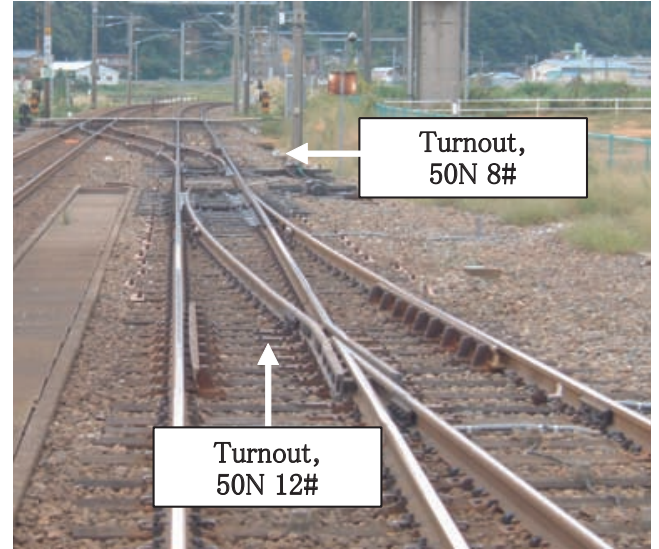

Fig. 3 Test site

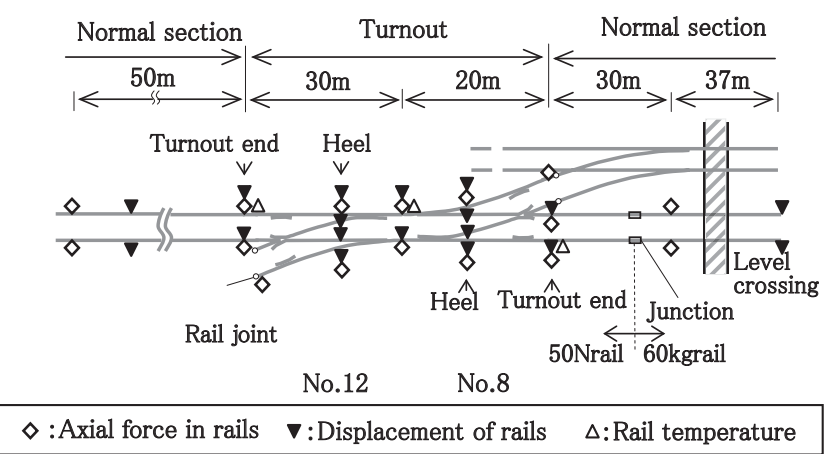

Fig. 4 Measurement position

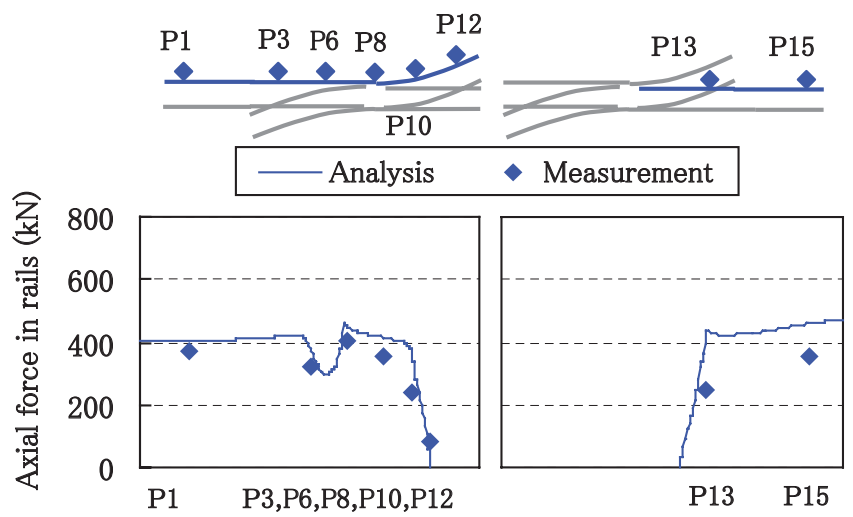

Fig. 5 Distributed axial force in rails

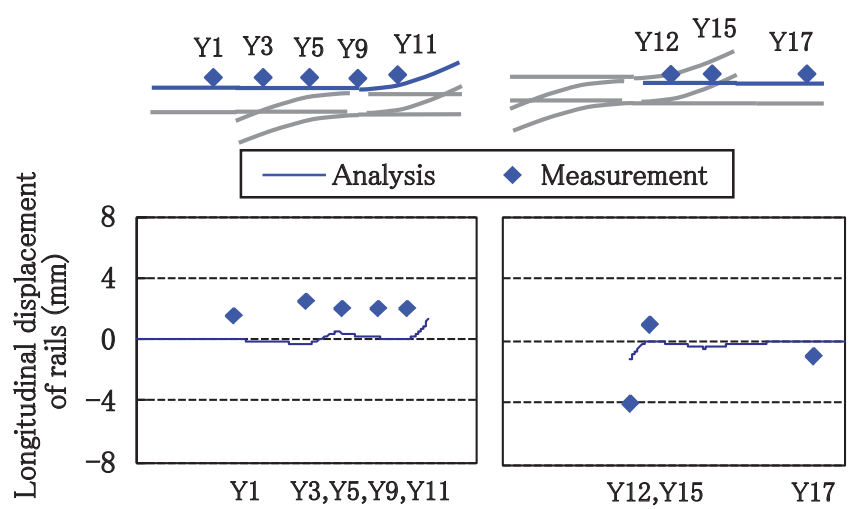

Fig. 6 Distributed longitudinal displacement of rail turnouts was calculated using (1) and (2) and the relationship between resistance and displacement was approximated by (3) and (4). As for the resistance of sleepers in the normal section neighboring the turnouts, longitudinal resistance was assumed to be $7.8 \mathrm{kN} / \mathrm{m}$ and lateral resistance was assumed to be $3.9 \mathrm{kN} / \mathrm{m}$ which is the minimum value necessary for laying CWR.

Figures 5 and 6 compare the results of calculation with those of the test. In Fig. 5, it can be seen that the calculated axial force approximately corresponds to that in the tests, and the analysis method is therefore verified. In Fig. 6, the absolute values of the calculated longitudinal rail displacement are smaller than those of the test results. This was presumably caused by the allowance between the tie plate and the sleeper of the turnout and the fact that the rail was not sufficiently fastened to the sleepers in the test site.

Table 1 Analysis condition

\begin{tabular}{|c|c|}
\hline Item & Specifications \\
\hline Rail type $^{*}$ & JIS $50 \mathrm{kgN}$ rail \\
\hline Track model length & $563 \mathrm{~m}$ \\
\hline Temperature change & $+26.7^{\circ} \mathrm{C}$ \\
\hline Distance between two turnouts & $0 \mathrm{~m}$ \\
\hline Tie space in normal section & $641 \mathrm{~mm}$ \\
\hline Tie space in turnouts & Drawing for design \\
\hline $\begin{array}{c}\text { Asymptotic value of } \\
\text { longitudinal resistance in } \\
\text { normal section }\end{array}$ & $7.8 \mathrm{kN} / \mathrm{m} /$ rail \\
\hline $\begin{array}{l}\text { Asymptotic value of lateral } \\
\text { resistance in normal section }\end{array}$ & $3.9 \mathrm{kN} / \mathrm{m} /$ rail \\
\hline $\begin{array}{l}\text { Coefficient for longitudinal } \\
\text { and lateral resistance } \\
\text { (See also Eqs.3 and 4) }\end{array}$ & $1 \mathrm{~mm}$ \\
\hline $\begin{array}{c}\text { Rotational spring coeffient in } \\
\text { normal section }\end{array}$ & $23800 \mathrm{~N} \cdot \mathrm{m} / \mathrm{rad}$ \\
\hline Restrain spring coefficient & $6 \times 10^{4} \mathrm{kN} / \mathrm{m}$ \\
\hline
\end{tabular}

\subsection{Analysis for several two turnouts layouts}

Axial force was calculated for four layout patterns of two turnouts integrated with CWR on ballast as shown in Fig. 7. The analysis conditions are shown in Table.2. Two cases for each pattern were calculated: one in which only a stock rail on the straight line was welded and another in which stock rails both on the straight and on the branch line were welded.

The calculated results are shown in Fig. 8. The maximum axial force in rails occurs at the heel in the stock rail or the lead rail, depending on the layout pattern. The maximum ratio of the maximum axial force in the rails to that in the normal $\mathrm{CWR}$ section $\left(637 \mathrm{kN}\right.$ for $\left.\Delta \mathrm{T}=+35^{\circ} \mathrm{C}\right)$ is 1.32 in the case where only that the stock rail on the straight line was welded, and 1.39 in the case where stock rails both on the straight and on the branch line were welded.

As described above, rail axial force and longitudinal displacement can be calculated for various layout patterns of multiple turnouts integrated with CWR on ballast. The 


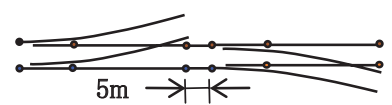

(a) Case 1

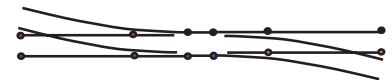

(c) Case 3

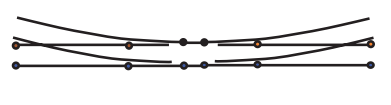

(b) Case 2

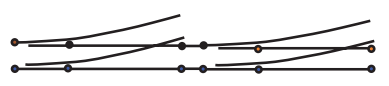

(d) Case 4
Fig. 7 Layout of turnouts integrated with CWR on ballasted track

Table 2 Analysis condition

\begin{tabular}{|c|c|}
\hline Item & Specifications \\
\hline Rail type* $^{*}$ & JIS $60 \mathrm{~kg}$ rail \\
\hline Track model length & $574 \mathrm{~m}$ \\
\hline Temperature change & $+35^{\circ} \mathrm{C}$ \\
\hline Type of two turnouts & $60 \mathrm{~kg}$ rail 12\# \\
\hline Distance between two turnouts & $5 \mathrm{~m}$ \\
\hline Tie space in normal section & $641 \mathrm{~mm}$ \\
\hline $\begin{array}{c}\text { Asymptotic value of } \\
\text { longitudinal resistance in } \\
\text { normal section }\end{array}$ & $7.8 \mathrm{kN} / \mathrm{m} /$ rail \\
\hline
\end{tabular}

* Other specifications are the same as those in Table. 1

Case in which stock rail only on the straight line was
welded
$\square$ Case in which stock rails both on the straight and
branch lines were welded

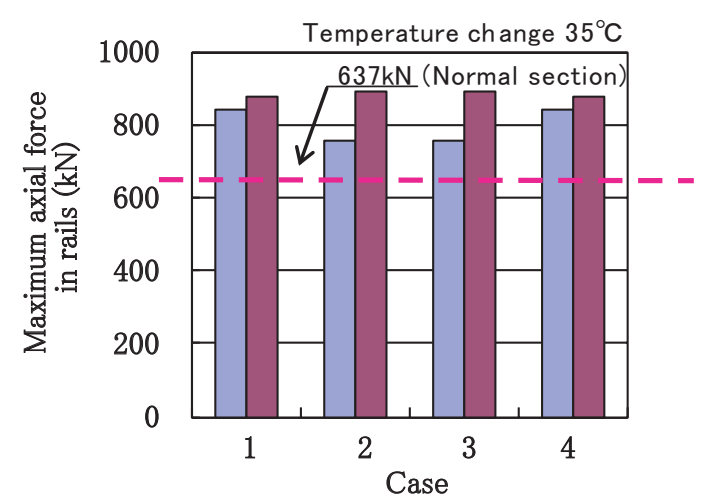

Fig. 8 Calculated maximum axial force in rails for each case

necessary lateral resistance of sleepers and measures to increase it can be examined on the basis of the calculated results.

\section{A CWR track integrated with a turnout equipped with ties directly fastened to viaducts}

\subsection{Test of longitudinal resistance of track}

In the case of a turnout installed on ties that are directly bolted to the concrete roadbed of viaduct, rails are rigidly fastened to the ties using washers, as shown in Fig. 9. Resistance to rail-creepage at the fastening device is greater than that in normal directly fastened track, i.e., 5 $\mathrm{kN} / \mathrm{m} /$ rail. A loading test to measure resistance to rail-

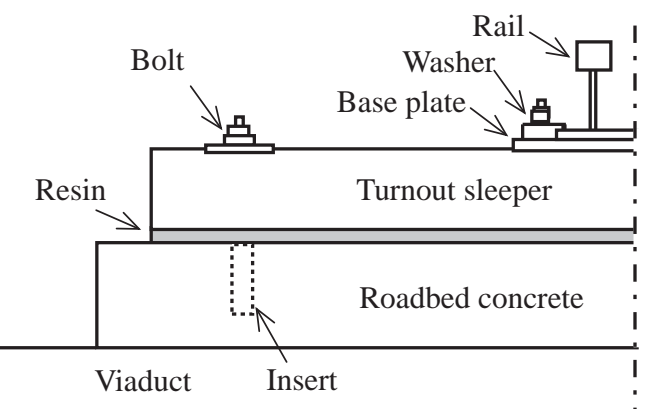

Fig. 9 Cross-section schematic of the fastening device used in a turnout with ties directly fastened

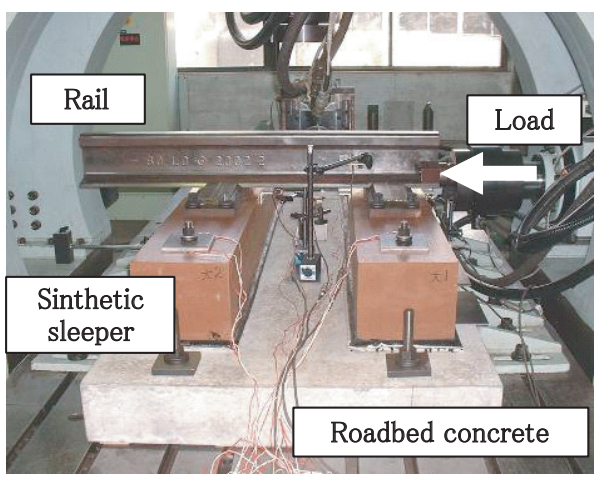

Fig. 10 Test overview

Table 3 Rail-creepage resistance

\begin{tabular}{|c|c|ccc|}
\hline \multirow{2}{*}{ Case } & $\begin{array}{c}\text { Fastening } \\
\text { device } \\
\text { type }\end{array}$ & $\begin{array}{c}\text { Rail-creepage resistance } \\
\text { Per fastening } \\
\text { device }\end{array}$ & $\begin{array}{c}(\mathrm{kN} / \mathrm{m}) \\
\text { Per rail unit } \\
\text { length }\end{array}$ \\
\hline \hline 1 & $\begin{array}{c}\text { washer in } \\
\text { a lead rail }\end{array}$ & 30.3 & 55.0 \\
\hline 2 & $\begin{array}{c}\text { washer in } \\
\text { a point }\end{array}$ & 15.8 & 28.7 \\
\hline 3 & $\begin{array}{c}\text { rail brace } \\
\text { in a point }\end{array}$ & 34.6 & 69.1 \\
\hline
\end{tabular}

creepage was carried out using a rail fastened to two ties fixed to a concrete block, which was fixed to a rigid bed with anchor bolts as shown in Fig. 10. The rail was loaded in the longitudinal direction and the load was increased until the rail moved rapidly in the longitudinal direction, i.e., until it crept at the fastening device. The test was carried out for three type of fastening device used in turnouts: a washer used in a lead rail, a washer used in a point and a rail brace used in a point.

The average maximum load for each fastening device is regarded as its rail-creepage resistance. The results shown in Table 3 indicate the force per unit length of the rail as obtained by dividing the average maximum test load by the tie spacing value of $1.1 \mathrm{~m}$.

\subsection{Analysis for a CWR track integrated with a turnout equipped with ties directly fastened to viaducts}

For a CWR track integrated with a turnout installed on ties directly fastened to viaducts, the force in the longitudinal direction interacting between girdors and track 
structure under conditions of temperature change may be larger than that for the normal CWR track directly fastened to the structure because of the difference in longitudinal resistance depending on track structure.

Analysis of axial force in CWR integrated with a turnout with ties directly fastened to viaducts was carried out. The parameters were the turnout position on the structure, girder length, and the position of the movable and

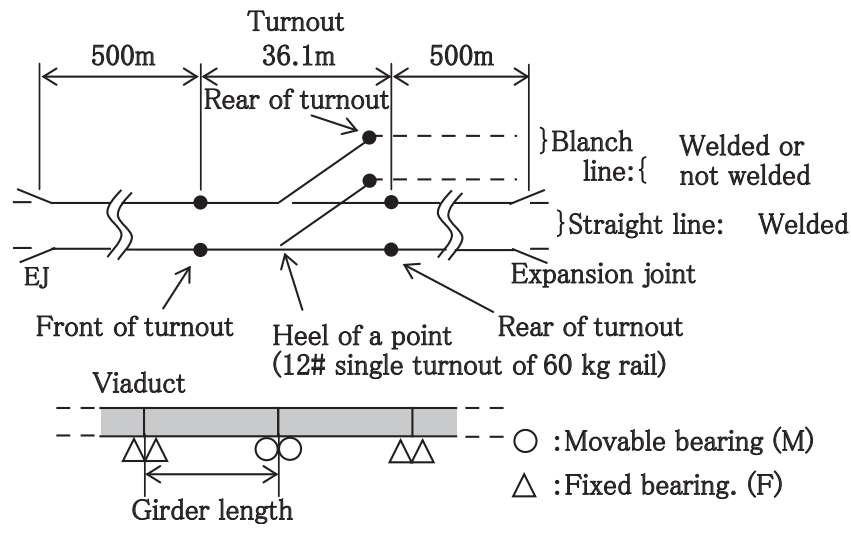

Fig. 11 Analytical diagram

Table 4 Analysis condition

\begin{tabular}{|c|c|c|}
\hline \multicolumn{2}{|c|}{ Item } & Specifications \\
\hline \multicolumn{2}{|c|}{ Rail type } & JIS $60 \mathrm{~kg}$ rail \\
\hline \multicolumn{2}{|c|}{$\begin{array}{l}\text { Linear expansion coefficient of } \\
\text { girder }\end{array}$} & $1.0 \times 10^{-5} /{ }^{\circ} \mathrm{C}$ \\
\hline \multicolumn{2}{|c|}{ Temperature change } & $+40^{\circ} \mathrm{C}$ \\
\hline \multirow{2}{*}{$\begin{array}{l}\text { Asymptotic } \\
\text { value of } \\
\text { longitudinal } \\
\text { resistance }\end{array}$} & $\begin{array}{l}\text { Normal section } \\
\text { on girder }\end{array}$ & $5 \mathrm{kN} / \mathrm{m} / \mathrm{rail}$ \\
\hline & Turnout & $\begin{array}{l}\text { See also result in } \\
\text { Section } 4.1\end{array}$ \\
\hline \multicolumn{2}{|c|}{$\begin{array}{c}\text { Coefficient for longitudinal } \\
\text { resistance (See also eq.3) }\end{array}$} & $1 \mathrm{~mm}$ \\
\hline \multicolumn{2}{|c|}{ Restrain spring coefficient } & $6 \times 10^{4} \mathrm{kN} / \mathrm{m}$ \\
\hline \multicolumn{2}{|c|}{ Girder length } & $25,50,100 \mathrm{~m}$ \\
\hline
\end{tabular}

\begin{tabular}{l}
\hline$\square$ Case in which only the stock rail on the straight \\
line was welded \\
$\times+$ Case in which stock rails both on the straight and \\
branch lines were welded
\end{tabular}

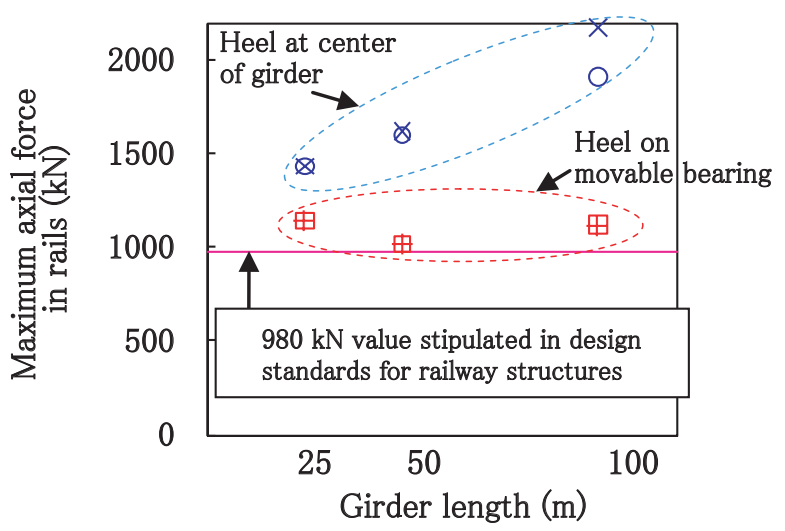

Fig. 12 Calculated maximum axial force in rails for each case fixed girder bearings. Two cases for each layout pattern were calculated: one in which only a stock rail on the straight line was welded and another in which stock rails both on the straight line and on the branch line were welded. The analysis conditions and bearing positions are shown in Fig. 11 and Table 4. Assumptions for the analysis were as follows:

1) The analysis was made for $12 \#$ single turnout using a $60 \mathrm{~kg}$ rail on the meter gauge line.

2) The movable end of the CWR to be taken into account in the calculation was positioned far $(500 \mathrm{~m})$ from the turnout.

3) Bearings were laid in an FF/MM pattern and the girder temperature change was equal to that of the rails.

4) The heel of the point was located on a movable bearing or at the center of a girder.

Figure 12 shows the relationship between girder length and the calculated maximum axial force in the stock rail on the straight line for each case. The maximum axial force for the case where the heel on the movable bearing exceeded the $980 \mathrm{kN} /$ rail value stipulated for normal track directly fastened to a structure in the design standards for railway structures is larger than that for the case where the heel was at the center of a girder, and the former increases with girder length.

\subsection{Analysis of a CWR track integrated with two turnouts equipped with ties directly fastened to viaducts}

Analysis of axial force on a CWR track integrated with two turnouts equipped with ties directly fastened to viaducts was carried out. The heel of the point of one turnout was located on a movable bearing and only the stock rail on the straight line was welded. The movable end of the CWR was positioned far from the turnout in the same way as for the calculation in Section 4.2. The analytical conditions are shown in Table 5 , and there was zero distance between the two turnouts.

The distributed axial force in the stock rail on the straight line is shown in Fig. 13. Axial force rapidly increased and decreased and exceeded the $980 \mathrm{kN}$ prescribed for normal section in design standards for railway structures as mentioned in Section 4.2.

As described above, the axial force in CWR track and the load acting on girders can be calculated for various

Table 5 Analysis condition

\begin{tabular}{|c|c|c|}
\hline \multicolumn{2}{|c|}{ Item } & Specifications \\
\hline \multicolumn{2}{|c|}{ Rail type } & JIS $60 \mathrm{~kg}$ rail \\
\hline \multicolumn{2}{|c|}{$\begin{array}{c}\text { Linear expansion coefficient of } \\
\text { girder }\end{array}$} & $1.0 \times 10^{-5} /{ }^{\circ} \mathrm{C}$ \\
\hline \multicolumn{2}{|c|}{ Temperature change } & $40^{\circ} \mathrm{C}$ \\
\hline \multirow{2}{*}{$\begin{array}{l}\text { Asymptotic } \\
\text { value of } \\
\text { longitudinal } \\
\text { resistance }\end{array}$} & $\begin{array}{c}\text { Normal section } \\
\text { on girder }\end{array}$ & $5 \mathrm{kN} / \mathrm{m} /$ rail \\
\hline & Turnout & $55 \mathrm{kN} / \mathrm{m} / \mathrm{rail}$ \\
\hline \multicolumn{2}{|c|}{$\begin{array}{l}\text { Coefficient for longitudinal } \\
\text { resistance (see also Eq. 3) }\end{array}$} & $1 \mathrm{~mm}$ \\
\hline \multicolumn{2}{|c|}{ Restrain spring coefficient } & $6 \times 10^{4} \mathrm{kN} / \mathrm{m}$ \\
\hline
\end{tabular}




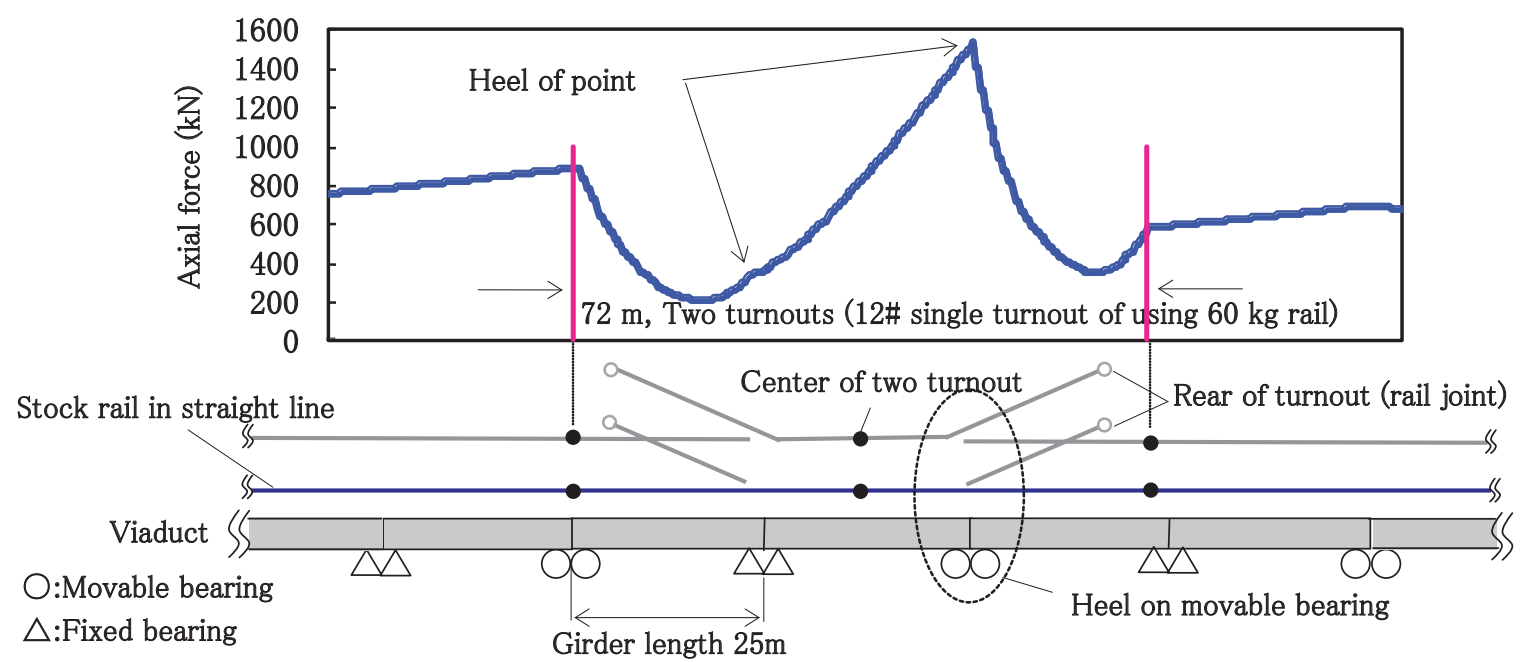

Fig. 13 Distributed Axial force of CWR integrated with two turnouts equipped with ties directly fastened

layout patterns of multiple turnouts integrated with CWR on the structure.

\section{Conclusions}

To expand the application range of continuous welded rail integrated with turnouts on ballasted track or turnouts with ties directly fastened to viaducts, an analysis method was developed and verified using field test results. The necessary conditions for CWR connected with a turnout directly fastened to viaducts were evaluated, the following results were obtained:

1. An analysis method was developed using the finite element method in order to evaluate axial force and longitudinal displacement of CWR integrated with turnouts installed in succession on ballasted track or track with ties directly fastened to viaducts.

2. The calculated axial force of CWR roughly corresponds to that obtained in the field tests, and the axial force of CWR can be calculated for various layout patterns of multiple turnouts integrated with CWR. The necessary level of lateral resistance for sleepers and measures to enhance it can be examined on the basis of the calculated results.

3. Axial force of CWR can be evaluated for various girder lengths and bearing positions in the case of multiple turnouts with ties directly fastened to viaducts integrated with CWR

4. The analysis results indicated that locating a turnout in center of a girder is advantageous in the case of a turnout with ties directly fastened to viaducts integrated with CWR.

5. The maximum axial force of CWR may exceed the 980 $\mathrm{kN}$ value stipulated for normal track directly fastened to structures in the design standards for railway structures. Accordingly, the force interacting between girders and track structure and lateral stability against track buckling need to be investigated in detail.

\section{References}

[1] Miura, S. and Yanagawa, H., "Characteristics of Axial Force in Rail at Turnout Integrated with Continuous Welded Rail," QR of RTRI, Vol.30, No.4, November, 1989.

[2] Takatani H., Satou, Y. and Suzuki, S., "Temperature Rising Test of Turnout," Railway Technical Research Pre-report, No.A-87-214, 1987 (in Japanese). 